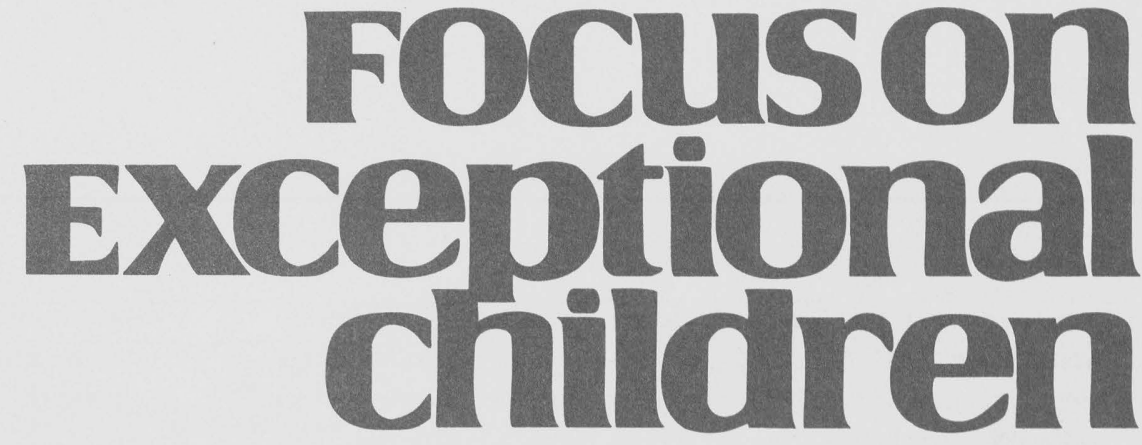

\title{
The Role of Assessment in Qualifying Students as Eligible for Special Education: What Is and What's Supposed To Be
}

\section{Donald L. MacMillan, Frank M. Gresham, Kathleen M. Bocian and Gary N. Siperstein}

Since PL 94-142 was signed into law by President Gerald Ford in 1975, three procedures have to be followed in sequence:

1. The child has to be qualified as eligible for special education and related services by meeting criteria for one of the sanctioned disability categories.

2. A "free appropriate public education" (FAPE) must be provided for in the formalized individual Education Plan (IEP), which specifies short-term and long-term goals agreed upon as appropriate, and the services and supports required to achieve them.

3. The setting in which FAPE is to be accomplished is to be specified in keeping with the principle of least restrictive environment (LRE).

This article is concerned with the first requirement, qualifying students as eligible for special education and related services. Moreover, the focus is on high-incidence disability cases in which qualification is highly dependent on assessment of children using psychometric instruments and scales.

Two clearly different routes can be defined whereby children come to be qualified, or diagnosed, as eligible for special education. We specify Route 1 as being traversed by children whose disability is detected soon after birth or during the first few years of life. Children diagnosed via Route 1 include, among others, those with Down syndrome, cerebral palsy, autism, and severe sensory impairments. These cases typically are diagnosed by physicians employing medical histories, physical examinations, and laboratory tests to arrive at the diagnosis.

Frequently these children participate in early childhood programs for children with disabilities and arrive at the public schools with a diagnosis and transition plan in hand. The public schools "accept" the diagnosis and set about designing an IEP for the child. Students traveling Route 1 tend to exhibit "visible" disabilities, professionals tend to agree concerning the validity of the diagnosis, and the students who come to the public schools with a diagnosis tend to remain in the disability category throughout their public school careers.

A second route to be described has been followed more commonly by children identified as having mild mental retardation (MMR), learning disabilities (LD), emotional and behavioral disorders (EBD), and speech and language impairments (SLI). These frequently are

Donald MacMillan, Frank Gresham, and Kathleen Bocian are with the University of California at Riverside. Gary Siperstein is with the University of Massachusetts, Boston. 
referred to as the "high-incidence disabilities." Although some cases served under each of these categorical headings are detected prior to enrollment in school, most of these children proceed through the preschool years "on schedule" for developmental tasks. There are few or no indicators of a disability for parents and preschool teachers to note. These children enter public schools as "normal" and are detected only after they fail to fulfill the role of the "normal student" (Ashurst \& Meyers, 1973; Mercer, 1973).

What is important to recognize in cases proceeding through Route 2 is that they:

- are qualified by school personnel (usually members of a multidisciplinary team, which we refer to herein as a Student Study Team [SST]),

- are detected only after failing to make adequate progress in the general education program,

- are qualified, or diagnosed, on the basis of their educational history, psychometric measures, and observation, and

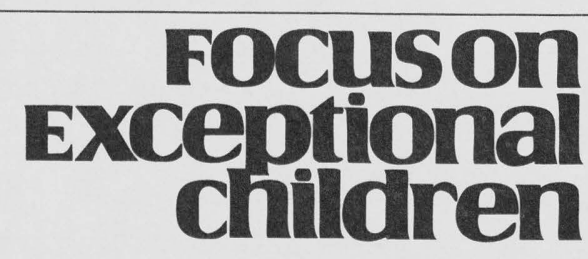

ISSN 0015-511X

FOCUS ON EXCEPTIONAL CHILDREN (USPS 203-360) is published monthly except June, July, and August as a service to teachers, special educators, curriculum specialists, administrators, and those concerned with the special education of exceptional children. This publication is annotated and indexed by the ERIC Clearinghouse on Handicapped and Gifted Children for publication in the monthly Current Index to Journals in Education (CIJE) and the quarterly index, Exceptional Children Education Resources (ECER). The full text of Focus on Exceptional Children is also available in the electronic versions of the Education Index. It is also available in microfilm from Xerox University Microfilms, Ann Arbor, MI. Subscription rates: Individual, \$30 per year; institutions, \$40 per year. Copyright (C) 1997, Love Publishing Company. All rights reserved. Reproduction in whole or part without written permission is prohibited. Printed in the United States of America. Periodicals postage is paid at Denver, Colorado. POSTMASTER: Send address changes to:

$$
\begin{gathered}
\text { Love Publishing Company } \\
\text { Executive and Editorial Office } \\
\text { P.O. Box } 22353 \\
\text { Denver, Colorado } 80222 \\
\text { Telephone (303) 757-2579 }
\end{gathered}
$$

Edward L. Meyen University of Kansas

\section{Richard J. Whelan}

University of Kansas Medical Center
Glenn A. Vergason Georgia State University

Thomas Love Associate Editor
- are among the less impaired cases one finds in the schools being served under the various categorical headings, particularly in contrast to those arriving via Route 1.

In this article we are restricting our treatment to students represented by Route 2 because they constitute the cases in which issues of assessment are most relevant. Cases of a more severe nature that are labeled via Route 1 do not require finegrained distinctions; their disabilities are evident to most everyone and, except in cases of multiple disabilities, there is agreement among those concerned with regard to the category in which the child belongs.

In our analysis we will examine the relationship between authoritative definitions of disabilities, the federal and state regulations presumed to guide local education agency (LEA) practices, assessments conducted that are designed to measure the criteria specified in the regulations, and the use made of the assessment data in assigning children to disability categories and thereby qualifying them as eligible for special education. We also will present data from an ongoing project concerned with classification of children referred as "at-risk" and examine the relationship between criteria specified in regulations and the children classified by the schools under various categorical headings.

Further, we provide an explanation for the lack of congruence between how the process is supposed to work and how the process actually is employed. We provide an alternative model that, in our opinion, describes more accurately what the schools actually do in sorting students. Finally, we conclude with a discussion of the pros and cons of present school practices and the policy implications thereof.

\section{MODEL LINKING DEFINITIONS, STATE REGULATIONS, AND DIAGNOSTIC PRACTICES}

The schematic shown in Figure 1 reflects a conceptualization of how authoritative definitions (Box A) influence the federal and state regulations (Box B), defining and guiding the diagnosis of children with disabilities. We suggest that the schools are guided by these regulations and engage in qualifying children as special education eligible by essentially "matching" child characteristics to the criteria specified in the state regulations in efforts to determine whether a child is eligible for special education as LD or mentally retarded (Box C). In turn, this process should result in a population of children (Box D) under each State-sanctioned disability category (e.g., LD) that meet the definitions and criteria specified in regulations and, in turn, meet the authoritative definition. We examine this model here in terms of the extent to which it de- 


\section{A}

Authoritative definitions specifying parameters of children to be included in a disability class e.g., AAMR, DSM-IV, NJCLD)

\section{$\checkmark$}

\section{B}

Definitions adopted in federal definition \& state education codes

Criteria specified in state education codes required to establish eligibility under a state-santioned disability category

\section{$\downarrow$}

Characteristics of children enrolled in a program designed to serve children with a particular disability (e.g., EMR, LD)

\section{FIGURE 1 Assumed Model Linking Definitions to Characteristics}

scribes what actually goes on in the assessment and classification process prescribed in federal and state regulations.

\section{Influence of Authoritative Definitions on Federal and State Regulations}

In the fields of mental retardation, learning disabilities (LD), and emotional and behavioral disorders (EBD) are $a u$ thoritative definitions. Typically, these definitions are crafted by committees composed of nationally acknowledged academicians and clinicians. For example, AAMR has provided several definitions over the years of mental retardation drafted by its Committee on Terminology and Classification (see MacMillan \& Reschly, 1996). In the field of LD, authoritative definitions have been proposed by the National Advisory Committee on Handicapped Children (1968), the National Joint Committee for Learning Disabilities (1981), with revisions being suggested by the Interagency Committee (Kavanagh \& Truss, 1988).

A slightly different situation is present in the area of EBD, as the term "serious emotional disturbance" (SED) is the special education category, whereas psychiatric diagnoses are guided by the Diagnostic and Statistical Manual (American
Psychiatric Association, 1994). Many children who meet criteria under the DSM (e.g., oppositional defiant disorder, depression) may not qualify as SED because of various exclusionary considerations (see Forness \& Knitzer, 1992, for discussion). Our point here is that authoritative definitions are supposed to be definitive, specifying the behavioral dimensions on which children "in" the disability category differ from those who do not qualify.

Authoritative definitions have been influential in the formulation of definitions of disability categories in IDEA and in state education codes. For example, Frankenberger and Fronzaglio (1991) reported that $64 \%$ of the states cited the Grossman (1973) AAMR definition in their education code definitions of mental retardation. That definition reads: "Mental retardation refers to significantly subaverage general intellectual functioning existing concurrently with deficits in adaptive behavior, and manifested during the developmental period" (Grossman, 1973, p. 5). The authoritative definition produced by the NACHC (1968) was adopted in the federal regulations authored by the U. S. Office of Education (1977), defining LD (Mercer, Jordan, Allsopp, \& Mercer, 1996). That definition reads:

"Specific learning disability" means a disorder in one or more of the basic psychological processes involved 
in understanding or in using language, spoken or written, which may manifest itself in an imperfect ability to listen, think, speak, read, write, spell, or to do mathematical calculations. The term includes such conditions as perceptual handicaps, brain injury, minimal brain dysfunction, dyslexia, and developmental aphasia. The term does not include children who have learning problems which are primarily the result of visual, hearing, or motor handicaps, of mental retardation, or emotional disturbance, or of environmental, cultural, or economic disadvantage. (USOE, 1977, p. 65083)

Mercer, Hughes, and Mercer (1985) found that $72 \%$ of the states used the 1977 definition or a variation thereof-a trend that has persisted to the present time, as $71 \%$ were found to use the same in the most recent survey (Mercer et al., 1996). The linkage between authoritative definitions and federal and state regulations defining MR and LD are fairly evident as most states have modeled their definitions and criteria after those suggested in authoritative definitions. We conclude that the influence (shown by arrow from Box A to Box B in Figure 1) of authoritative definitions on federal and state regulations has been established.

\section{Regulations and the Relationship to Diagnostic Criteria}

State regulations tend to go beyond defining the disability conditions as they specify criteria to be employed at the LEA when certifying a child as eligible for special education. Hence, the distinction between children "defined" as mentally retarded or LD is clear. LD refers to unexpected low achievement, whereas MR refers to low achievement accompanied by low aptitude - that is, it is expected low achievement.

The actual procedures used to identify children as eligible, however, are what operationalize the "degree" to which the achievement is unexpected-in the case of LD, ranging from "shock" to "modest surprise." These procedures relegate the identification process to be measurement bound, whereas the definitions are conceptually bound (Keogh \& MacMillan, 1996). Some states operationalize the discrepancy between aptitude and achievement in terms of standard score discrepancies of $11 / 2$ standard deviations; others use regressed discrepancies of 1 standard deviation. In the case of mental retardation, the cutoff score for IQ defining the upper limit varies-with some states using IQ 70, others IQ 75, and others (e.g., Iowa) still using IQs in the 80s.

Several features in the definitions of mental retardation and LD warrant consideration. We refer here to the "exclusion" clauses in the definitions of LD. Keogh (1994) noted that definitions of LD have had in common two features that we will later discuss. First, the condition is taken as "evidence of in- child, presumably causal, neurological conditions" and also "they distinguish learning disabilities from other problem conditions such as mental retardation, and from low achievement resulting from economic or social conditions or motivational/emotional influences" (p. 16). Conversely, mild mental retardation has long been linked intimately to economic or social conditions. One of the strongest correlates of this form of mental retardation is low social class (MacMillan, Siperstein, \& Gresham, 1996). We will return later to this distinction: that LD excludes low socioeconomic conditions as a causal factor, whereas mild mental retardation is found most often in children coming from just such conditions.

We conclude that the congruence between behavioral domains stressed in federal and state definitions and criteria specified for use in diagnosis (arrow from Box B to Box C in Figure 1) is clearer in the case of mental retardation than in LD. This is because of the tendency to stress psychological processes in the definitions along with discrepancies, while diagnostic criteria required for diagnosis of LD rely heavily on discrepancies and seldom specify how psychological processing deficits are to be operationalized. Nevertheless, state definitions of disability conditions and the criteria required in diagnosis have some degree of correspondence.

Now we turn to an ongoing project in which we have been involved to examine the linkage between Box C and Box Dthe extent to which the schools employ the criteria specified in the state regulations to diagnose students as mentally retarded or LD.

\section{UCR ALTERNATIVE ASSESSMENT PROJECT FINDINGS}

For the past several years the first three authors have been involved in a project examining classification of students in the primary grades by the public schools. One purpose of that investigation has been to examine the congruence between psychometric profiles modeled after California regulations defining mental retardation and LD with actual eligibility decisions reached by the schools on these children. Over a 2year period we selected a sample of 150 students, stratified by ethnic group, who were referred by their general education teachers to Student Study Teams (SSTs), which prescribe prereferral interventions and evaluate the effectiveness of these intervention efforts. It is the SST that recommends a child be formally evaluated for special education eligibility if the prereferral interventions are judged to be ineffective. The students selected for study were chosen on the basis of being referred to SST, and not on the basis of the likelihood that they would subsequently be placed in special education. We have 


\section{TABLE 1}

\section{Demographics for Sample of Children Referred to School Study Team}

\begin{tabular}{llcl}
\hline Ethnicity/Gender & $\underline{\mathrm{n}}$ & Mean $\mathrm{CA}^{*}$ & $\mathrm{SD}$ \\
\hline White & & & \\
$\quad$ Male & 31 & 9.02 & 1.01 \\
$\quad$ Female & 24 & 8.84 & 0.86 \\
Black & & & \\
$\quad$ Male & 30 & 8.81 & 0.83 \\
$\quad$ Female & 13 & 9.35 & 1.19 \\
Hispanic & & & \\
$\quad$ Male & 28 & 9.11 & 1.11 \\
$\quad$ Female & 24 & 8.70 & 1.01 \\
\hline
\end{tabular}

$\mathrm{CA}=$ Chronological Age

reported on the characteristics of the referred sample and examined differences by gender and ethnicity (MacMillan, Gresham, Lopez, \& Bocian, 1996). Table 1 shows the breakdown of the sample by gender and ethnic group.

Soon after being selected, all participants were administered a battery of psychometric instruments, and we asked general education teachers to complete ratings on the students. Information in school records also was recorded, using the School Archival Records Search (SARS) (Walker, BlockPedego, Todis, \& Severson, 1991). A listing of all instruments and scales administered to the students or completed by teachers is given in Table 2. Using the data collected, we classified all subjects as mentally retarded, $\mathrm{LD}$, or ineligible for special education. We will refer to these as Project Classifications.

The criteria we employed in each case were consistent with the criteria specified in the California State Department of Education regulations for children served as mentally retarded or learning disabled. In the case of mental retardation, the IQ cutoff employed was a Full Scale IQ (FSIQ) $\leq 75$, and in the case of $\mathrm{LD}$, we required an FSIQ $>82$ and a standard score discrepancy of 22 points ( $11 / 2$ standard deviations) between the WISC-III FSIQ and any WRAT-R subtest score (Reading, Arithmetic, or Spelling). Detailed descriptions of the criteria, the gender, and ethnic breakdown qualifying as mentally retarded and LD, and findings, are available in recent publications concerned with mental retardation (MacMillan, Gresham, Siperstein, \& Bocian, 1996) and LD (MacMillan, Gresham, \& Bocian, in press).

\section{TABLE 2 \\ Instruments Employed in UCR Alternative Assessment Project}

\begin{tabular}{ll}
\hline Administration & Instrument \\
\hline Administered to student & WISC-III (Wechsler, 1991) \\
& Wide Range Achievement \\
& Test-Revised (Jastak \& \\
Wilkinson, 1984) \\
Completed by teacher & Social Skills Rating Sys- \\
& tem (Gresham \& Elliott, \\
& 1990) \\
& Critical Events Index (from \\
& SSBD, Walker \& Sever- \\
& son, 1992) \\
School records by project & School Archival Records \\
staff & Search (Walker et al., \\
& 1991) \\
\hline
\end{tabular}

NOTE: Other scales and instruments were used in the project but are not referenced in this article.

As a result of performing the Project Classifications, we were able to designate a given child as eligible for special education by virtue of qualifying as mentally retarded or as LD. In addition to Project Classifications, we were interested in how the schools decided on individual students, which we refer to as School Classifications. As these individual cases were monitored by the SSTs, various "outcomes" resulted. Some students responded favorably to the prereferral interventions and were dropped from the caseload of the SST. These cases were considered "ineligible" according to School Classifications. In other cases a child resisted the prereferral interventions and was recommended by the SST to be formally evaluated. In these cases the formal evaluation and the SST decision could be for the child to be classified as mentally retarded or LD, or the evidence and the SST still could conclude that, despite resisting prereferral interventions, the child was ineligible for special education.

In the current article, we consider students who were School Classified as mentally retarded, LD, or ineligible. The schools, however, did not reach decisions on all 150 students we were able to provide with Project Classifications. In some cases, between the time we administered scales to the students and the school reached a decision on the child, the child moved. In some other cases, the schools still have not arrived at any decision (the case is "pending") for a variety of reasons. 
For example, some children have been absent so often that the SST does not think the prereferral intervention has been given a fair test; in others, the parents have failed to attend required meetings; in yet others, issues of language and bilingualism are being considered cautiously. As a result, we have both Project Classifications and School Classifications on 113 of the 150 subjects.

\section{Mental Retardation}

Let us first consider the children we found to meet the State-specified criteria as mentally retarded. Of the 150 children studied, we found 43 who achieved FSIQ $\leq 75$ and who had been referred by their general education teachers for being unable to keep up with the rest of their classmates. It is noteworthy that more than $28 \%$ of the students referred to SSTs achieved FSIQs that qualified them psychometrically as mentally retarded, suggesting that the students resembling mildly mentally retarded students continue to present problems to general class teachers and are referred for additional help. Of these 43 , a grand total of six were classified by the schools as mentally retarded.

It is evident that the public schools of California are not using the diagnostic category of "mental retardation" for many students with mild mental retardation. In 35 cases of referred children with FSIQs of 75 or less, a decision has been reached by the public schools. These are displayed in Table 3. Visual inspection reveals that only six $(17.1 \%)$ of those with subaverage intelligence were classified as mentally retarded, and two of these cases involved black students.

Recall that, because of the Larry P. provisions, the SST did not have our WISC-III data. Nor could they have considered IQ data from other prohibited tests of intelligence in arriving at these classifications decisions. A total of $19(51 \%)$ students from this group (having an IQ of 75 or less) were classified as LD. The California Education Code requires a 22-point discrepancy between measures of aptitude and achievement to qualify as LD. Only six of the 19 classified by the schools as $\mathrm{LD}$, however, exhibited the requisite discrepancy.

Also recall that one of the elements defining LD was that the learning problems were not to be attributable to mental retardation-all 19 such cases presented with FSIQs that were below the state cutoff defining mental retardation. Six other children, despite being referred and achieving a FSIQ $\leq 75$, were judged as ineligible for, or not needing, any special education services.

Clearly, the public schools in California classify few students as mentally retarded. The diagnostic category is being used almost exclusively for children who are diagnosed via

\section{TABLE 3 \\ School Classification of Students Referred to SSTs Achieving FSIQs $\leq 75$}

\begin{tabular}{lr}
\hline School Classification & Number \\
\hline Ineligible or Never Assessed for & \\
Any Special Education & 6 \\
Mental Retardation & 6 \\
Learning Disabled & 19 \\
Speech/Language & 4 \\
\hline TOTAL & 35 \\
\hline NOTE: FSIQ refers to Full Scale IQ achieved on WISC-III, and School \\
Classifications are the State-sanctioned disability category un- \\
$\quad$ der which the child was deemed eligible for special education \\
$\quad$ services.
\end{tabular}

Route 1 (indications at birth or during infancy or preschool years), and only a handful of children are assigned the label via Route 2. Nevertheless, it is evident from the pool of students referred to SSTs that students with low general intelligence who encounter severe and persistent learning difficulties are a major concern to general education teachers. Just under $30 \%$ of the referred sample studied in this project achieved FSIQs of 75 or less. It just happens that in California these students are not being classified as mentally retarded.

\section{Learning Disabilities}

Project classifications of the 150 students revealed 46 students with a FSIQ of 82 or higher, and who had a 22 point discrepancy between their WISC-III FSIQ and at least one of the WRAT-R subscale scores. These 46 students are considered Project Classified as LD. The first question addressed was whether the use of psychometric instruments and calculation of the severe discrepancy prescribed in California yielded significantly different rates of LD eligibility for the population of students referred to SSTs. Table 4 shows the distribution of cases qualifying as LD from among the referred samples. These rates are not significantly different for any of the three ethnic groups (MacMillan et al., in press). The percent of referred children who qualified as LD by project standards was $30.7 \%$, compared to the slightly over $28 \%$ qualifying as mentally retarded. The dramatic differences in "rates" reported in the Annual Reports to Congress are not consistent with the almost identical rates found here. 


\section{TABLE 4 \\ Project-Identified Students with LD by Ethnic Group}

\begin{tabular}{lcccc}
\hline Project Classification & White & Black & Hispanic & Total \\
\hline LD & 20 & 10 & 16 & 46 \\
Not LD & 35 & 32 & 37 & 104 \\
\hline TOTAL & 55 & 42 & 53 & 150 \\
\hline$\%$ LD & $36.4 \%$ & $26.2 \%$ & $30.2 \%$ & $30.7 \%$ \\
\hline
\end{tabular}

As noted previously, the schools arrived at eligibility decisions in 113 of the 150 total cases referred to SST. The schools qualified 61 students as LD. The breakdown by ethnic group is shown in Table 5. Tests to determine whether the proportion of referred children in any ethnic group school identified as LD was greater than was true for other ethnic groups failed to exhibit any reliable differences (MacMillan et al., in press). Although the project identifications, modeled after the state criteria, suggested that approximately $30 \%$ of the total sample of 150 qualified as LD, the schools identified more than $50 \%$ (61 of 113 for whom decisions were reached) of the students as LD. Whereas the schools were reluctant to qualify children who met state criteria as mentally retarded, they identified as LD many students who failed to meet the state criteria.

This apparent discrepancy between children identified by the schools as LD and those qualifying according to State reg-

\section{TABLE 5}

\section{School-Identified Students with LD by Ethnic Group}

\begin{tabular}{lcccc}
\hline School Decision & White & Black & Hispanic & Total \\
\hline LD & 24 & 18 & 19 & 61 \\
Not LD & 23 & 13 & 16 & 52 \\
\hline TOTAL & 47 & 31 & 35 & 113 \\
\hline \% LD & $51.1 \%$ & $58.1 \%$ & $54.3 \%$ & $54.0 \%$ \\
NOTE: In 113 cases the schools actually made the decisions regard- \\
ing eligibility. In the remaining 37 cases, the children either \\
moved between the time they were assessed by project staff \\
and any decision being made or the case was still pending at \\
the time of this writing.
\end{tabular}

ulations was examined by casting the cases of the 113 cases where actual school decisions were reached into the $2 \times 2$ contingency table shown in Table 6 . Visual inspection reveals that the extent of congruence is a bit underwhelming. One way to examine this table visually is to consider that the two shaded cells represent cases in which project classifications and school classifications are in agreement. Hence, the decisions in 74 of the 113 cases, students who were classified $e i$ ther LD or ineligible by the schools, were consistent with State guidelines. The 39 cases "off the diagonal" represent cases in which the school's decision seems incongruent with criteria specified in State regulations.

\begin{tabular}{|c|c|c|c|}
\hline \multirow[b]{2}{*}{ School-Identified } & \multicolumn{2}{|c|}{ Project-Identified } & \multirow[b]{2}{*}{ Total } \\
\hline & LD & Not LD & \\
\hline LD & 29 & 32 & 61 \\
\hline Not LD & 7 & 45 & 52 \\
\hline TOTAL & 36 & 77 & 113 \\
\hline
\end{tabular}

At this point, let us invoke some terms in order to discuss the four cells contained in the $2 \times 2$ Table 6 . In the top left cell, project and school classifications of the children as LD agree; we will refer to these cases as Agree $L D$. In the bottom right cell, project and school classifications agree that the children are ineligible; we refer to these cases as Agree Ineligible. The top right cell contains the cases the schools called LD but the project criteria indicated that they did not qualify as LD; we refer to these cases as False Positives. Finally, the cases in the bottom left cell represent those situations in which the schools called the child ineligible but the project criteria indicated that these children met the state criteria for LD; we refer to these cases as False Negatives. We compared these four groups on several behavioral dimensions to examine what accounted for these "outcomes." Figure 2 through Figure 4 are bar graphs showing the level of performance of the four groups on IQ (Figure 2), achievement (Figure 3), and behavior (Figure 4).

In the present article we will focus on the patterns of the findings without detailing the analyses that were performed; 


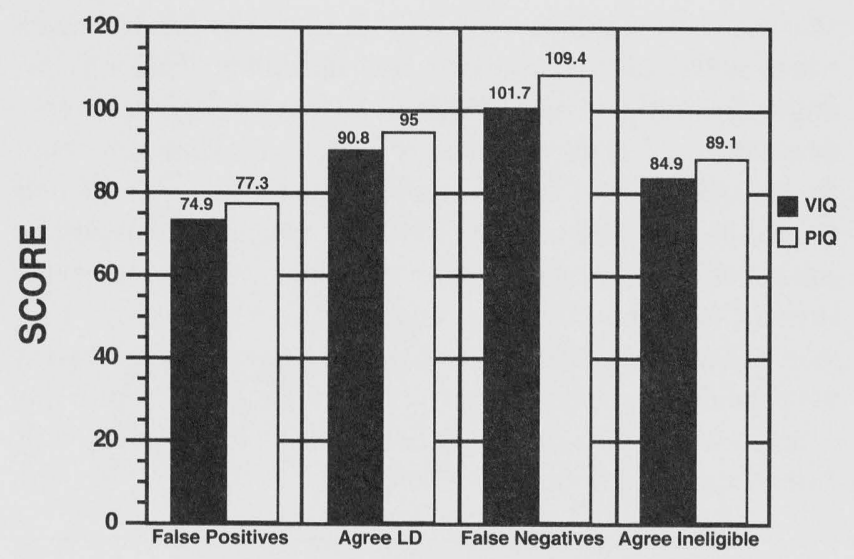

FIGURE 2

\section{WISC-III Scores X LD Category}

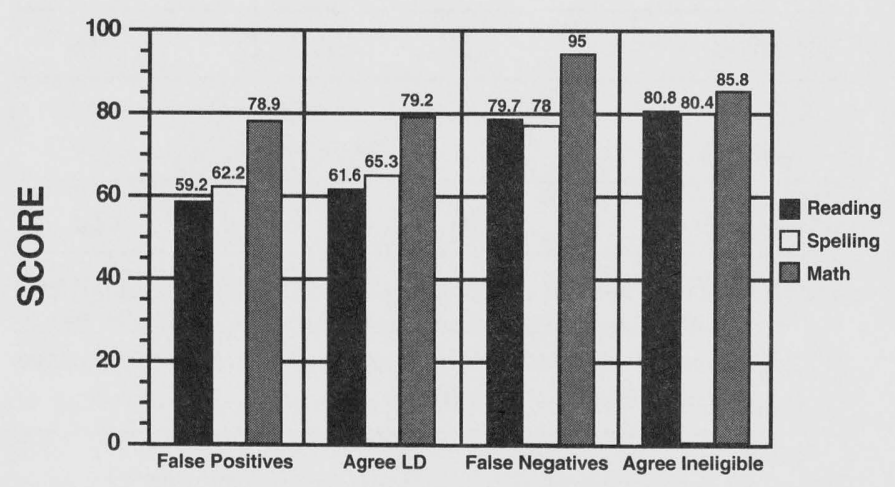

the interested reader can find this detail in MacMillan et al. (in press). In Figure 2 one can see rather dramatic differences in both VIQ and PIQ between the False Positives and False Negatives. The low IQs found for the False Positive group of children is explained by the fact that many of the children classified as mentally retarded were, in fact, classified as LD by the schools to qualify them for special education without appending a label perceived to be pessimistic. On the other hand, the False Negative group's high IQs are believed to reflect the fact that, despite a significant discrepancy between aptitude and achievement, the schools failed to classify these students as LD because their absolute level of achievement did not deviate as markedly from class norms, making them "less difficult to teach."

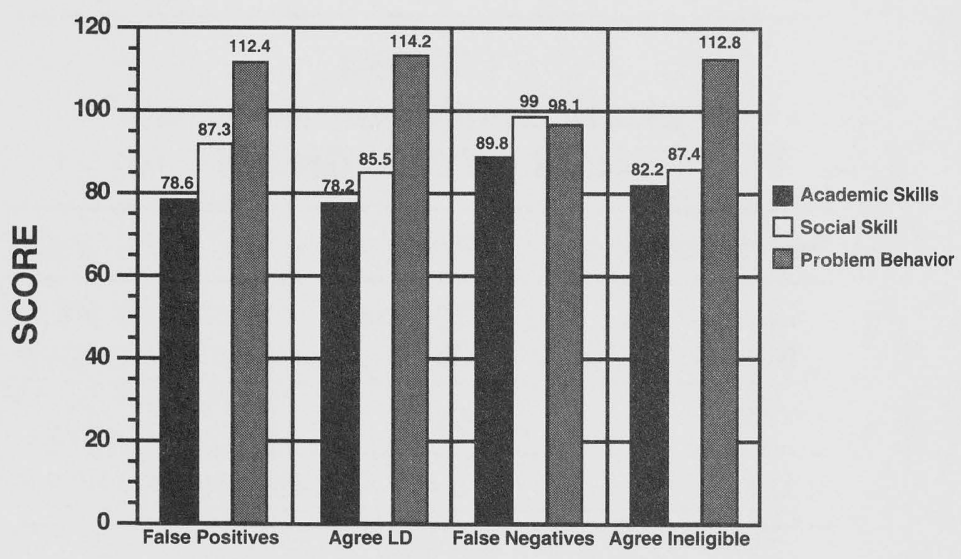

FIGURE 4

WISC-III Scores X LD Category

Figure 3 provides additional support for this conclusion. The False Positives and the Agree LD groups (the two groups on the left of the figure) represent the children the schools classified as LD. These two groups do not differ from one another on their absolute levels of achievement in reading, spelling, or arithmetic. Despite the significantly lower IQs found for the False Positives, the absolute level at which they are reading, computing, and spelling is comparable to that of the Agree LD students. Moreover, the False Positives and Agree LD groups differ significantly from both other groups that the school did not identify as LD (the False Negatives and Agree Ineligible), which, in turn, did not differ significantly from one another on their achievement scores.

We interpret this pattern to reflect a perspective on the part of the schools that "an LD" is a child whose absolute level of achievement presents serious problems to the general education teacher, differs significantly from that of general education peers in whose class the child is enrolled, and resists the intensity of treatments feasible in the context of a regular class. Moreover, we interpret this pattern to reflect a perspective on the part of the schools regarding what "an LD is not." It is not necessarily the child described in the authoritative definitions and federal and state regulations! That is to say, the group of youngsters classified as LD by the schools contains significant numbers of children who fail to exhibit the requisite discrepancy between aptitude and achievement. In addition, that group includes significant numbers of children whose learning problems appear because of mental retardation or social and cultural factors. If the child's level of achievement indicates that he or she needs help, the schools 
classify that child as LD regardless of whether he or she meets the specified criteria prescribed in the state regulations. What a novel idea—giving help to a student who needs it!

Intellectual level and achievement level do not tell the whole story. If one considers behavioral ratings provided by general education teachers, we see that there are differences between certain of the groups on certain behavioral dimensions. On two of the SSRS-T scales (Academic Competence and Social Skills), the higher score indicates "better" performance, and on Problem Behaviors the higher score indicates the presence of "more" behavior problems. With that in mind, consider the pattern of findings shown in Figure 4. The two groups comprising the school-identified LD do not differ from one another on any of these three scales; however, they both differ significantly from the False Negatives group on all three scales, with the False Negatives exhibiting fewer behavioral problems, better social skills, and better academic competence. Interestingly, the Agree Ineligible group differed from any of the other three groups on only one subscale; the Agree Ineligible groups exhibited significantly more problem behaviors than did the false negative group. One reason we suspect the Agree Ineligible group was referred was because of their behavior (Problem Behaviors), which teachers rated as comparable to those exhibited by the students the schools classified as LD.

\section{Conclusions Based on the UCR Alternative Assessment Project Findings}

To the extent that our results inform the topic of the role of assessment in the diagnosis of high-incidence disabilities, we believe our findings confirm that the linkage between Statespecified criteria and professional behavior at the LEA level is extremely weak. LEA practices in certifying students as eligible for special education bear little, if any, resemblance to the prescribed processes in the State regulations. At the most superficial level, however, LEA practices might appear to conform to state regulations. For example, instruments appropriate for measuring aptitude (intelligence) and achievement are administered and the scores recorded. These scores-not necessarily the scores provided by the research project-are those the schools use in "classifying" students.

Nevertheless, the use to which the scores derived from these instruments are put, and the extent to which criteria (e.g., the requisite 22 point discrepancy for LD eligibility in California) are followed in the diagnostic process, fail to justify the substantial dollar amount spent on collecting such data. Table 7 contains the project classifications for the students the schools classified as LD. Less than half of the stu- dents classified as LD qualified as LD only or LD in combination with another diagnosis (e.g., ADHD, EBD) not precluded by one of the exclusionary clauses, as would be true for mental retardation and LD. Ten cases classified by the schools as LD failed to qualify, according to project criteria, for any of the four child disability categories considered.

It is evident that if the process described in federal and state regulations for qualifying students as LD suggest rigid adherence to specific test score discrepancies (the WISC-III and WRAT-R, for example), they are not followed carefully by the schools when classifying students as LD. The schools however, do follow the guidelines in the sense that they often "scramble" to find a combination of tests that will yield the 22-point discrepancy or a processing disorder, often requiring them to administer additional scales at an added expense. If the child is seen as needing help, the committees will resort to various combinations of test scores to "justify" the child's eligibility.

As a result of the above situation, one has to raise questions about the role of assessment in the classification process that the schools employed. Clearly, classification decisions being

\section{TABLE 7 \\ School-Identified Students with LD and Their Project Classifications}

\begin{tabular}{lcc} 
Project Classification & No. Cases & Percent \\
\hline LD only & 20 & 32.8 \\
ADHD only & 3 & 4.9 \\
MR only & 10 & 18.0 \\
EDB only & 0 & 0.0 \\
LD and ADHD & 6 & 9.8 \\
LD and MR & - & - \\
LD and EBD & 0 & 0.0 \\
ADHD and MR & 6 & 9.8 \\
ADHD and EBD & 0 & 0.0 \\
MR and EBD & 1 & 1.6 \\
LD and ADHD and MR & - & - \\
LD and ADHD and EBD & 3 & 4.9 \\
ADHD and MR and EBD & 1 & 1.6 \\
None of the 4 & 10 & 16.4 \\
TOTAL & 61 & 100
\end{tabular}

NOTE: The combination of LD and MR in any combination is impossible because $\mathrm{IQ}<76$ was used to define $\mathrm{MR}$ and $\mathrm{an} \mathrm{IQ}>81$ was used to define LD. 
made at the LEA are driven by perceived need, not by test scores, and they find a way to meet the criteria even if that path to qualifying students exhibits huge measurement variability. Is the effort and cost expended to find a combination of scores to justify the decision based on perceived need really worth it? Unless we are comfortable with a situation in which LEA practices bear little, if any, resemblance to the regulations thought to guide classification at the LEA, one of two things may be needed.

1. One alternative is to conclude that we do, in fact, wish to serve those children described in the authoritative definitions and regulations and those who fail to meet specified criteria should not be served as LD. In that case, state education agencies (SEAs) should monitor more closely the LEA practices and insist that classification decisions conform to the eligibility criteria with standard assessment measures across the state.

2. An alternative approach is to agree that children who need help, regardless of whether they exhibit a 15-point or a 22-point discrepancy, can be classified as LD in order to qualify for help. In that case, the State regulations ought to be changed to reflect the actual practices at the LEA.

The effect of LEA classification practices has a profound impact on the "meaning" of the terms mental retardation and $L D$. The first author currently is involved in a court case in the state of Connecticut concerning children with mental retardation. In preparing for testifying, a number of school districts throughout the state, were visited, including visits to urban, suburban, and somewhat rural district, to observe children classified as mentally retarded. At each meeting with district special education directors and at each school site, LEA personnel were asked to point out a child currently classified as mentally retarded who was identified after enrolling at school as a "normal" student - that is, students classified via Route 2. Virtually no children bearing the label "mentally retarded" could be identified who were classified as such after enrolling in school.

This practice of reserving the classification of mental retardation for children whose intellectual limitations are severe and whose behavioral limitations are evident across settings (e.g., school, neighborhood, home) has resulted in schools' eliminating mild mental retardation as a diagnostic construct (MacMillan, Siperstein, \& Gresham, 1996). It explains, in part, the low prevalence of overall mental retardation in individuals of school-age in states such as California and Connecticut, as evidenced in child count data reported to Congress (U. S. Department of Education, 1995).
While the concept of mental retardation has become more restricted, the concept of $\mathrm{LD}$, evidenced by who is classified as such by the schools, has been expanded. Findings from our project illustrate that the schools are operationalizing $\mathrm{LD}$ as students with absolute low achievement, including students with levels of general intellectual functioning that are typically considered mentally retarded as well as students with a painstakingly or painfully derived aptitude that creates the required discrepancy.

Moreover, LD seems to be the "diagnosis of choice" for a nonspecific and undifferentiated category of children that general education teachers view as "difficult to teach," with a disregard for eligibility criteria for State-sanctioned disability categories. We will return later in this article to the potential consequences of this state of affairs.

As a consequence of the foregoing state of affairs, an interesting dilemma exists. On the one hand, schools are identifying and serving a significant number of children as LD who do not meet the definition of $L D$ and, technically speaking, are not supposed to be receiving special education services if they do not qualify. In addition, the schools are failing to identify a significant number of children as mentally retarded (some found outright ineligible and others being identified as LD) who do, in fact, meet the definition of mental retardation and who the State definition suggests would benefit from special education services (or different educational services) than they currently are being offered. This paradox should be addressed.

Finally, findings from this project inform the renewed concern about the use of intelligence tests with black students, evidenced by a series of workshops held by the National Research Council of the National Academy of Sciences (Morison, White, \& Feuer, 1996). Although Judge Peckham concluded in the Larry P. case that IQ is "primary and determinative" in classifying children as educable mentally retarded (EMR), data from our project suggest quite the opposite. Many students with IQs in the range eligible for classification were not classified as mentally retarded. Many students whose IQs are above cutoffs for mental retardation but whose achievement was not discrepant also were certified by the schools as learning disabled.

Our findings provide substantial support for the position that the data from tests of intelligence are of secondary importance to the absolute level of achievement and teacher perceptions that a given child is making inadequate progress and needs help. Moreover, our findings fail to support Judge Peckham's assertion that IQ is "determinative" for any ethnic group in our study. Children of all three ethnic groups whose IQ scores permitted qualifying them as mentally retarded were not so labeled. Furthermore, children exhibiting intraindividual discrepancies between IQ and achievement of a magnitude 
required for certification as LD were not qualified as LD by the schools. In these instances, the cases were primarily children whose absolute level of reading achievement, despite being discrepant from expected levels of achievement, was high enough that it probably did not differ significantly from the modal level of reading achievement in the child's class.

Has this "forced-fit discrepancy" between definitions and criteria of disability categories on the one hand and characteristics of the children the schools label as mentally retarded or LD always existed, or is it a relatively recent phenomenon? We believe that, in part at least, the explanation lies in changes that have occurred in special education procedures over the past 20 years. Let us turn to discuss some of these changes and how we believe they have altered the importance of assessment in the classification process the schools use today.

\section{HISTORICAL CHANGES IN THE IMPORTANCE OF ASSESSMENT IN CLASSIFICATION BY SCHOOLS}

The challenges leveled at the labeling, and educational treatment, of children with mild mental retardation (usually referred to as "educable mentally retarded" [EMR]) in the late 1960 s and 1970s is significant to an understanding of what has occurred. We contend that the assessment process at that time was a "high stakes enterprise"- high stakes in the sense that the psychometric profile of the child had consequences for: (a) the label that was appended to the child, and as a result, (b) the curriculum and/or services, along with (c) the administrative arrangement or placement of the child. Recall that this predates passage of PL 94-142 and the applications of free appropriate public education (FAPE), least restrictive environment (LRE), or individualized education plans (IEP).

Figure 5 depicts the consequences of being "diagnosed" into one of three classifications-EMR, TMR, and LD. Finegrained distinctions between EMR and LD, for example, had considerable consequences for the child in question.

Classification as EMR dictated, in turn, in what kind of administrative placement the child would receive services. To quote Robinson and Robinson (1965) in describing education services for EMR students in that era, "The consensus of special educators today definitely favors special class placement for the mildly retarded" (p. 466). Essentially, diagnosis as EMR carried with it a "packaged program"- and the package almost inevitably was an alternative, functional curriculum that differed markedly from the curriculum taught in general education. In fact, the position that special educators took then was that for children with mental retardation, unlike virtually every other disability, special education services modified not only how children were taught but also what they were taught. The various "EMR Curricula" (e.g., Hungerford's New York program, the Cincinnati curriculum) shared an emphasis on promoting prevocational and, later, vocational skills, social and interpersonal skills, and functional academics.

Hence, diagnosis as EMR in the 1960s resulted in a child being taught a "different" curriculum, which subsequently would be faulted by critics who observed that it made return to the general education population difficult, if not impossible, and made the assumption that all EMR children should receive the same curriculum. In addition, that curriculum almost invariably was taught in a self-contained special class or special day class (SDC). Hence, diagnosis as EMR carried with it placement consequences-placement in a SDC.

In a similar fashion, diagnosis as LD and TMR, too, had program and placement consequences. Typically, children diagnosed as LD continued to receive the general education curriculum, and services were designed to assist the child with processing problems by pulling them out of a general classroom to a resource room for remedial assistance from the resource teacher.

Thus, the differences between being diagnosed as EMR or LD were several. One diagnosis conveyed the belief that the general curriculum was appropriate (i.e., LD), and the other diagnosis (EMR) was predicated on the belief that an alternative curriculum was needed. Placement consequences also were noted, as LD students typically were served in a resource room pullout program.

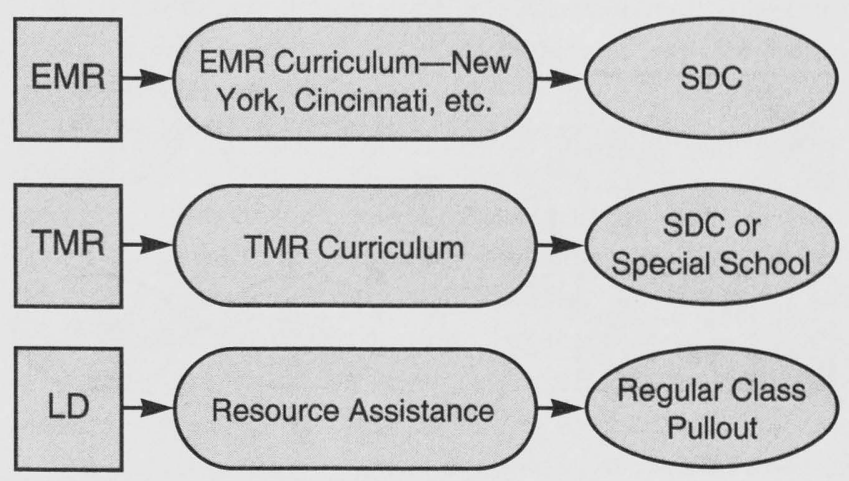

NOTE: State regulations were adhered to closely in differentiating: Diagnosis was linked to curriculum and placement. A flawed assumption is that all EMRs and TMRs are alike with identical programmatic needs.

\section{FIGURE 5}

\section{0s Perspective on Diagnosis}


For the child diagnosed as TMR, the resultant program and placement consequences were just as apparent. The TMR curriculum in the 1960s was matched to anticipated realistic goals for children described as ". . . not expected to achieve functionally useful academic skills. Self-care and social adjustment within a restricted environment are envisioned as the goals of their school experience" (Robinson \& Robinson, 1965 , p. 461). This curriculum typically was delivered to TMR children in one of two placements: either a TMR SDC on a regular school campus or placement in a special school serving only TMR or other children with moderate to severe disabilities.

The point to be emphasized is that during the 1960s the diagnosis, which relied heavily on assessment, was a highstakes venture because the specific diagnosis that was made resulted in a certain program and certain placement consequences. This state of affairs changed with the passage of PL 94-142, the Education for All Handicapped Children Act (EHA). When examining the consequences today of diagnosing a child as EMR, LD, or TMR, it is a situation very different from that existing prior to PL 94-142. EHA required that a child be found eligible for special education and related services by qualifying for one of the child disability categories. Diagnosis, however, no longer carried with it programmatic or placement consequences, as shown in Figure 6.

\section{Eligibility Program Curriculum Placement Category}

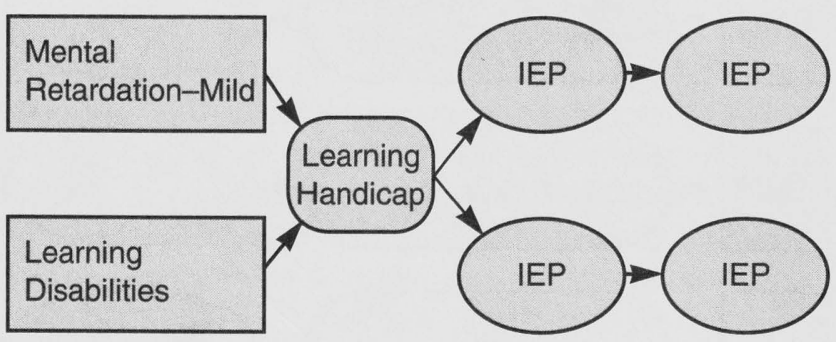

Diagnosis only establishes eligibility; curriculum, goals, and placement are negotiated independently during formulation of the IEP.

\section{FIGURE 6 1990s Perspective on Diagnosis}

\section{Changes Under IDEA}

At present, a child must be qualified as eligible for special education and related services by meeting one of the existing child disability categories. No longer does categorical eligibility carry with it either curricular or placement consequences. Instead, the Individuals with Disabilities Education Act (IDEA) requires that once a child is deemed eligible for special education by qualifying for a child disability category, the IEP process will be the means by which to negotiate the "appropriate" portion of FAPE. In the IEP process, short-term and long-term goals are specified and the supports and services needed to accomplish those goals are specified.

Unlike the 1960s, when diagnosis as EMR carried with it the EMR curriculum and placement in the special day class, today a diagnosis of mental retardation carries with it no specific program or placement. That will be negotiated during the IEP process. Similarly, being found eligible by virtue of qualifying as LD only entitles a child to have an IEP drawn up but carries with it no particular programmatic or placement consequences. Because the curriculum deemed appropriate does not hinge on the diagnosis, and placement is determined on the basis of the least restrictive environment (LRE) provisions of IDEA, diagnosis into one of the disability categories is no longer a "high stakes" venture.

\section{Changes in Classification by LEA}

In the UCR Alternative Assessment Project findings, we sought to examine the extent to which classification decisions made at the school level yielded children whose psychometric profiles met the criteria specified by the State for mental retardation and LD. Recall that we found rather low degrees of congruence, which could be interpreted in different ways. It might suggest that LEA practices are out of compliance. It also could suggest that Student Study Teams relied more heavily on information other than that collected in the assessment process. We believe that the historical changes noted above are implicated in the state of affairs we found.

Discussions with public school representatives ranging from state directors of special education to district special education directors to classroom teachers, concerning why so few children with IQs below the cutoff for mental retardation were certified, met with a common message. One state director commented, "There is no upside to calling a child mentally retarded." The term is considered demeaning by parents, the prognosis held by many is pessimistic, and the program and services that child needs can be justified whether he or she is labeled mentally retarded or LD. 
Teachers gave us similar input, which we reported in one article (MacMillan, Gresham, Siperstein, \& Bocian, 1996). Teachers were careful to state that the lack of congruence between State criteria for mental retardation and who gets classified in various child disability categories should not be taken to reflect carelessness or sloppy practices. Instead, they argued that it reflects a series of shared beliefs that influence LEA practices, including the following:
(a) They live with assessments, as necessary evils, be- cause that is the mandated process in order to get serv- ices to children; (b) they are more concerned with "what to do" than with "what kind of kid this is"; (c) they find the diagnostic criteria and the measures of these criteria to lack "instructional validity"; and (d) they believe IQ is no longer well-respected and perceive the label of mental retardation as extremely pessimistic in its prognosis. (MacMillan, Gresham, Siperstein, \& Bocian, 1996, pp. 170-171)

In short, teachers are more concerned with getting assistance for children they perceive to need assistance than they are in implementing a sorting process they perceive to exclude children who need help and lacking instructional validity. So, although regulations require that certain behavioral dimensions be assessed with certain instruments, the required assessment process is followed with a "gentle nudge" toward assessments that will document a discrepancy.

Some observations seem in order regarding classification of high-incidence cases in the public schools.

1. School-based Student Study Teams have all but ceased to use mild mental retardation as an educational diagnosis for students who enter school undetected as eligible for special education. Instead, the LD designation is being used as a nonspecific and undifferentiated designation permitting a widely heterogeneous group of students to be certified as eligible for special education.

2. Committees responsible for certifying eligibility of these students as LD appear not to consider IQ and achievement simultaneously in arriving at classification decisions. That is to say, academic achievement and behavior seem to constitute the two most important domains evaluated in arriving at eligibility decision; however, the level of achievement does not seem to be interpreted relative to the child's aptitude. Instead, LD is being used to serve students with absolute low achievement regardless of whether the level of achievement is discrepant from some expected level or whether the low achievement appears congruent with subaverage general intellectual functioning.

Findings from our project revealed that students with significant discrepancies between IQ and achievement were not certified as LD by the SST when the absolute level of achievement was "rather" high (see the False Negative figures in Figure 4). That is, the special education "slots" were reserved for the children with the absolute lowest achievement. Apparently these students are viewed as more in need of help by teachers than are students with a profile in which the achievement level is discrepant from IQ but is not at an absolute low level relative to other students at that school site.

The findings from our investigation led us to conclude that the sorting process does not proceed along lines specified in State education codes with strict adherence to the criteria specified. The pattern of findings also forced us to rethink just how the schools are sorting children into special education. If we could characterize this process, questions inevitably would arise as to whether this is a "good" process or whether it contains unforeseen pitfalls. Essentially, we concluded that the schools operate according to what we describe as a Titration of Intensity of Treatment Model, which we will now describe.

\section{RESISTANCE TO TREATMENT AS A BASIS FOR CLASSIFICATION}

An understanding of the group of children served as mildly mentally retarded and LD clearly requires study of the referral process (Bahr, Fuchs, Stecker, \& Fuchs, 1991; MacMillan, Gresham, Lopez, \& Bocian, 1996; Tobias, Zibrin, \& Mendell, 1983; Zigmond, 1993). Students who are not referred by their general education teachers never will be certified as eligible for special education, and an understanding of what leads to teachers' referring certain students and not referring others is fundamental to understanding the population of children ultimately served in special education.

Our findings suggest that general education teachers define "difficult to teach" in terms of absolute level of achievement and problem behaviors, primarily externalizing behaviors. In essence, students whose academic performance lags well behind classmates and students whose behavior is disruptive or threatening to the smooth running of the general education classroom are at-risk for being referred to prereferral interventions (MacMillan, Gresham, Lopez, \& Bocian, 1996).

Another way of viewing this situation is to consider that the general education teacher has focused those resources available in the general class in efforts to remedy the academic deficiencies the child exhibits and has done what he or she could to control behavior. These efforts are limited to what is feasible in a general education class with 30 or 35 students. When those efforts fail to result in acceptable levels of achievement or behavior, the teacher concludes that this child's behavior is resistant to the supports and services available in general edu- 
cation. At this point, the teacher refers the child to the Student Study Team.

Figure 7 is a schematic representing how treatments are titrated and how a child who resists one treatment is subsequently moved to a treatment that is more intense until a level of intensity is reached that successfully addresses the problems the child presents.

The schematic attempts to show the possible resources that can be brought to bear for a difficult-to-teach child in a general education classroom. Essentially, these treatments are rather "weak" in terms of amount of individual attention that can be devoted to the child and the expertise of the individuals delivering the treatment. Once the child has been referred to the Student Study Team, efforts designed to address the child's problem are directed at that individual child. A number of children in prereferral interventions, however, are resistant (they do not improve) to the treatment and persist in presenting the problems that initially brought them to the attention of the general education teacher. At this point (prereferral interventions have been tried and judged to be ineffective) the child would be referred by SST for formal evaluation and assessment.

As described previously in this article, the assessment is mandated by the State if a child is going to be eligible for special education services. The school psychologist would administer the scales necessary to document the child's eligibility, including a test of intelligence, an individually administered achievement test, and a measure of adaptive behavior (if mental retardation), along with the other information that would be compiled in doing a complete evaluation.

Our point here is that when a child has resisted the interventions available in the general education classroom and resisted the prereferral intervention efforts, he or she is a likely candidate to be qualified as eligible for special education services by the schools even if data from a rigorous source (the project psychometric profile) fail to meet State eligibility criteria. Our data show clearly that the schools get help for those students they believe need help, and eligibility criteria are massaged when they contraindicate the perception of need for this child.

To get more intensive services than were available in prereferral, we suggest that the overwhelming majority of children certified as eligible for special education in the early elementary grade are so certified as LD. Our findings showed that a substantial proportion of the students referred to SST and who scored under IQ 75 were designated by the schools as LD. Moreover, we found that a majority of those designated as LD by the schools failed to demonstrate the IQ-achievement discrepancy required in our project psychometric profile. Essen-

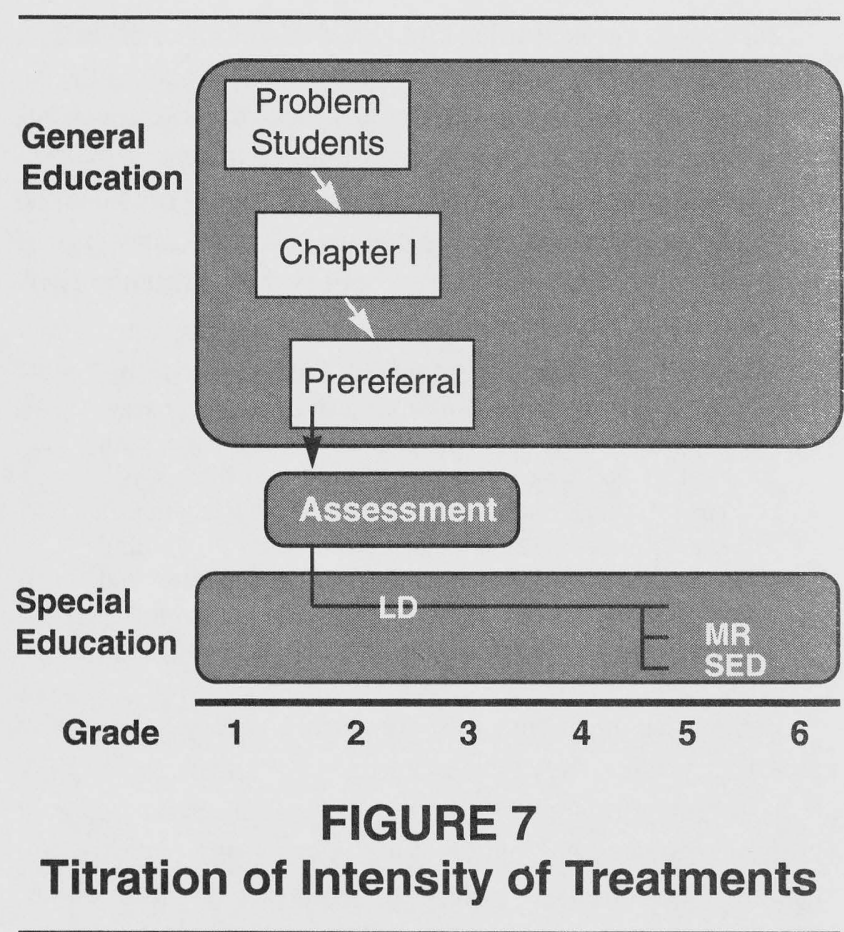

tially, the students designated as LD by the schools had in common one characteristic: absolute low achievement.

In addition, we observed that the initial "treatment" provided this LD population is typically a pullout resource service for a limited duration (e.g., 2 to 4 hours per week). This is more intense than what they received in prereferral intervention; however, over time we have seen the need for more intensive services for certain of the children. That is to say, for some of the LD-labeled groups, 2 to 4 hours of resource help did not result in significant improvement. For this group of children we see progressive increases in the duration of the resource specialist help (i.e., increased to 6 to 8 hours per week). The resistance to treatment, not any psychometric profile from the assessment, is what results in the increased duration of services. Stated differently, the ongoing informal assessment of progress in reading or improvement in deportment is what dictates changes in treatment.

At the bottom right portion of Figure 7, we provide our best guess as to how children who resist prereferral intervention and resist resource special help on a pullout basis are likely to be served in the remaining elementary grades. Some children will present with such severe academic problems-which appear across all subject-matter areas-that pullout resource services will be judged ineffective. For this segment, the schools, with agreement from parents, might conclude that the 
child needs an alternative curriculum, and some children will either (a) continue being certified as LD but enrolled in a special day class, or (b) be reclassified as mentally retarded.

For those who presented with behavior problems, we have some evidence (Duncan, Forness, \& Hartsough, 1995) based on 85 children and adolescents served as SED in two counties of California. At the time these students initially were certified as eligible for special education, $53 \%$ were designated as LD, $31 \%$ as SED, $11 \%$ speech and language impaired, and $5 \%$ in other categories. Evidence presented in this article is consistent with our Titration of Intensity of Treatment Model. Those authors reported the age when a problem was first noticed, the age at which the first intervention was initiated, the age at which first special education IEP was developed, and the age at which first SED placement was made. SED placement was found to occur some 4 to 6 years after the problem was first noticed. Those authors characterized this process for the "typical" SED student as follows:

His problems first came to the attention of someone outside the family when he was about 5 years old. Formal intervention for these problems was initiated when he was about $61 / 2$, and his first special education placement occurred when he was about 8 . . . There was a likelihood that his initial special education diagnosis was in the learning disability category, but he was ultimately found to be eligible as SED. (p. 17)

Again, we find LD being used as an initial, and unspecific, designation for children who are referred for being "difficult to teach" and resisting interventions available in the general education context. The diagnostic categories of mental retardation and SED, possibly a result of their being viewed as more pessimistic in their prognosis, seem to be employed only later in the school years when a pattern of behavior is well established and resistance to treatments provided under the LD rubric prove to be ineffective.

If the Titration of Intensity of Treatment model describes accurately how the schools are sorting children into the various disability categories, traditional assessments as currently conducted contribute little to the decision-making process. Findings from our project suggest strongly that IQ scores are disregarded when it comes to either concluding a child has subaverage general intellectual functioning or as a basis for establishing "expected" levels of reading or arithmetic achievement. Gresham and Witt (1997) wrote:

Estimates suggest that between 1 and 1.8 million intelligence tests are administered individually to children each year in the United States. Recent survey data suggest that two-thirds of a school psychologist's time is spent in special education eligibility determination and the typical school psychologist administers over 100 individual tests of intelligence each year. (Gresham \& Witt, 1997). (p. 249)

Estimating the cost of such assessments in man-hours when the data generated do not appear to be relied upon in arriving at classification decisions suggests that maybe those dollars could be spent in ways that would more directly guide the treatments provided these children. Even the most ardent defendants of intelligence testing never have argued that the scores derived provide any insight into the child's instructional needs. Rather, defendants argued that intelligence tests have utility for classification.

If IQ scores are not being used in a consistent fashion (which our data clearly suggest), however, and they are not instructionally relevant, we are hard-pressed to justify their continued use on a wholesale basis. Maybe it is time to explore alternatives to assessment of static child attributes and to acknowledge the contextual nature of most high-incidence disabilities as opposed to conceptualizing them as "withinchild" problems.

Along the lines of alternative approaches to assessment we offer an approach described by Fuchs (1995) as being far more consistent with how the schools actually operate. Space precludes a detailed discussion of her approach, but it approaches classification through a treatment validation framework. Curriculum-based measures (i.e., probes) are taken on an ongoing basis, and eligibility and placement are determined in a three-phase model.

1. She requires documentation of achievement discrepancies relative to local norms, tapping both absolute performance (level of performance) and growth (rate of growth over time). A child exposed to poor instruction in the previous year might score at a level below classmates, yet over time (e.g., 6 weeks) show a rate of growth (i.e., slope) comparable to that of classmates.

2. For children who compare unfavorably on both level and growth, Fuchs requires documentation that instructional changes in the regular education setting fail to produce adequate growth.

3. For children who are low on both level and slope in the first phase, and who do not make adequate growth with instructional changes in the regular education setting, Fuchs exposes the child to the instructional program available in a special education setting. For children who, with special education instruction, exhibit improvement she recommends placement.

The notion of testing whether what we offer in the name of special education services helps the child is unique. The ap- 
proach operationalizes in a far more systematic way what our project found to be going on in schools today. It also expands the perspective to consider rate of acquisition, not just level of performance, and utilizes trial periods as tests of whether the child will respond favorably to the services provided in the special education setting.

\section{FINAL COMMENTS}

We noted earlier that two apparent solutions to the gap between what is and what is supposed to be seem reasonable. First, we can take the position that the classification of children into disability categories should follow the process outlined explicitly in authoritative definitions and State education codes. This position suggests that LEA practices are out of compliance and steps should be taken to bring the schools into line. A second position suggests that the regulations and State education codes should be modified to reflect actual practices and the criteria that are really used in certifying students as eligible for special education. If the latter approach were followed, it seems that some position must be taken on use of the LD designation as an undifferentiated and nonspecific group of children. In discussions surrounding the reauthorization of IDEA, the idea of a noncategorical designation of children through the first several years of elementary school was considered. Let us explore this possible alternative to differential diagnosis.

One issue that keeps confronting us, particularly in the context of the high-incidence disabilities, is at what age, and based on what evidence, we make a classification decision with certainty. The proposal that we employ a noncategorical designation permits delaying the differential diagnosis as mentally retarded, speech and language impaired, or LD. As such, it inevitably will avoid some false positive classifications and might require those serving these children to recognize the great heterogeneity among the children and thereby necessitate individualization of prescriptions to an even greater extent than the IEP requirement provides for.

Let us consider, however, one subset of students who would be included in that noncategorical grouping: those who ultimately will require an alternative curriculum. Historically, we have recognized that children with mental retardation require modifications not only in how they are taught but also in what they are taught. Special education for students with mental retardation has consisted of a more functional curriculum believed to better prepare the child for the world of work and daily living. Certainly, we have become displeased with identification practices that rely heavily on IQ, particularly when done very early in a child's educational career.
If a noncategorical grouping is employed, one issue that arises is whether discrepant low achievers and nondiscrepant low achievers exhibit different trajectories in reading, for example, over time. If two students with very different IQs (e.g., 90 and 70) are reading at the same low level are "comparable" in reading at Time 1 (e.g., age 7), will these two students progress at the same rate given the same instruction? Invoking the perspective of Fuchs (1995), these two children are reading at the same level, and the question posed is whether they will demonstrate the same slope in reading improvement over the following 2 or 3 years. We believe that IQ differences do in fact contribute to one's ability to predict the slope of academic progress. Moreover, collection of data on actual progress via CBM measures is a more direct, cost-effective, approach that has greater "curricular validity." This approach does not require mandating IQ data on every child, as the same predictive information can be derived in most cases from direct assessment of the reading behavior.

Let us return to the issue that for some students a decision ultimately will be made that an alternative, more functional, curriculum is in order. In the past, the decision of who warrants a functional curriculum was based heavily on IQ level and subsequent classification as mentally retarded (as shown in Figure 5). Again, Fuchs' (1995) model recommends a trial period when the child who has resisted treatments available in general education (based on level of achievement and slope of gain) is provided services available in special education to determine whether these services resulted in an increased rate in the acquisition of reading skills. For children who exhibit an increase in rate of reading acquisition, placement into the special education program would seem to be in order. But some students who show low level and slope in general education fail to show an increase in slope when subjected to the special education treatment.

Consider a student who presents on the CBM approach as low in level of initial reading achievement and exhibits a slope significantly below that of classmates in the general class reading program. When provided the more intensive special education treatment, the student again fails to show appreciable gains in reading. Does this indicate that the child needs an alternative curriculum? Is this pattern of findings indicative of mental retardation? We suggest that for a child exhibiting this pattern of resistance to treatment, administering a test of intelligence might be appropriate at this point in the sequence (i.e., after a child fails to progress in an intensive special education reading program) to inform us whether the resistance to treatment is attributable to subaverage general intellectual functioning.

We are unaware of any longitudinal studies of referred atrisk students that examine developmental trajectories over 
time. Such studies, however, are crucial to our understanding of whether noncategorical groupings of children in the early elementary grades is more efficacious than categorical groupings that differentiate discrepant and nondiscrepant lowachievers.

The discussion of categorical groupings and the utility of traditional assessments in assigning students to categories must consider socioeconomic factors and linguistic diversity. The field of LD historically has dismissed children whose learning difficulties result from "socioeconomic disadvantage." Yet, evidence forthcoming from studies is compelling that many poor children are being classified as LD, particularly in urban school districts and districts serving large proportions of poor children (Gottlieb, J., Alter, Gottlieb, B., \& Wishner, 1994).

Furthermore, data from the UCR Alternative Assessment Project demonstrate that the diagnostic category of mental retardation is used rarely today for children whose disabilities go undetected until they enroll in public school. Moreover, substantial numbers of children classified as LD achieve IQs $<75$ and come from poor homes. LD, as defined by the schools, and low socioeconomic conditions are not mutually exclusive any longer-despite the exclusionary clauses found in most authoritative definitions of LD.

Given the association between low socioeconomic status and certain ethnic minority groups, the LD field must engage in an open discussion of the meaning of IQ scores for AfricanAmerican children and students from homes in which English is not the language spoken, in the same way that these issues were aired previously in the field of mild mental retardation. Regardless of whether an IQ score is used as a cut-off score defining mental retardation or whether it is used as the basis for estimating "expected" level of achievement in cases of $\mathrm{LD}$, the issue of potential bias in IQ when used with AfricanAmerican and Hispanic students is equally relevant. Whether children from differing ethnic, socioeconomic, or linguistic groups are "low" in their mastery of reading skills can, and is, documented effectively from direct assessment of those skills, and the evidence demands efforts to remedy the situation.

We question whether additional information yielded from tests of intelligence, or subsequent efforts to develop "better mousetraps" ""purer" measures of intellect or cognitive processing), will add much to addressing the question of how to remedy that situation. In a limited number of cases, which we describe above as resistant to virtually all interventions, the IQ data may identify situations in which continued efforts in promoting academic skills are futile and an alternative curriculum is indicated. The issue is captured in the distinction made by Speece and Harry (in press), who urge us to engage in classi- fication for children as opposed to classification of children, which is our current emphasis.

\section{REFERENCES}

American Psychiatric Association. (1994). Diagnostic and statistical manual of mental disorders (4th ed.). Washington, DC: Author.

Ashurst, D. I, \& Meyers, C. E. (1973). Social system and clinical model in school identification of the educable retarded. In G. Tarjan, R. K. Eyman, \& C. E. Meyers (Eds.), Sociobehavioral studies in mental retardation (pp. 150-163). Monographs of American Association of Mental Deficiency, No. 1.

Bahr, M. W., Fuchs, D., Stecker, P. M., \& Fuchs, L. S. (1991). Are teachers' perceptions of difficult-to-teach students racially biased? School Psychology Review, 20, 599-608.

Duncan, B. B., Forness, S. R., \& Hartsough, C. (1995). Students identified as seriously emotionally disturbed in day treatment: Cognitive, psychiatric, and special education characteristics. Behavioral Disorders, 20, 238-252.

Forness, S. R., \& Knitzer, J. (1992). A new propcsed definition and terminology to replace "serious emotional disturbance" in the Individuals with Disabilities Education Act. School Psychology Review, 21, 12-20.

Frankenberger, W., \& Fronzaglio, K. (1991). States' definitions and procedures for identifying children with mental retardation: Comparison over nine years. Mental Retardation, 29, 315-321.

Fuchs, L. (1995, May). Incorporating curriculum-based measurement into the eligibility decision-making process: A focus on treatment validity and student growth. Paper presented at workshop on IQ Testing and Educational Decision Making, National Research Council, National Academy of Sciences, Washington, DC.

Gottlieb, J., Alter, M., Gottlieb, B. W., \& Wishner, J. (1994). Special education in urban America: It's not justifiable for many. Journal of Special Education, 27, 453-465.

Gresham, F. M. \& Elliott, S. N. (1990). Social Skills Rating System. Circle Pines, MN: American Guidance Service.

Gresham, F. M., \& Witt, J. C. (1997). Utility of intelligence tests for treatment planning, classification, and placement decisions: Recent empirical findings and future directions. School Psychology Quarterly, 12, 249-267.

Grossman, H. J. (Ed.)(1973). Manual on terminology and classification in mental retardation. Washington, D.C.: American Association on Mental Deficiency.

Jastak, S. \& Wilkinson, N. (1984). Wide Range Achievement TestRevised. Wilmington, DE: Jastak Associates.

Kavanagh, J. F., \& Truss, T. J., Jr. (Eds.). (1988). Learning disabilities: Proceedings of the national conference (pp. 79-163). Parkton, MD: York Press.

Keogh, B. K. (1994). A matrix of decision points in the measurement of learning disabilities. In G. R. Lyon (Ed.), Frames of reference for the assessment of learning disabilities. (pp. 15-26). Baltimore: Paul H. Brookes. 
Keogh, B. K., \& MacMillan, D. L. (1996). Exceptionality. In D. Berliner \& R. Calfee (Eds.), Handbook of Educational Psychology (pp. 311-330). New York: Simon \& Schuster/Macmillan.

MacMillan D. L., \& Reschly, D. J. (1996). Issues of definition and classification. In W. MacLean (Ed.), Ellis' Handbook of mental deficiency: Psychological Theory and research (3d ed., pp. 47-74). Hillsdale, NJ: Lawrence Erlbaum.

MacMillan, D. L., Gresham, F. M., \& Bocian, K. M. (in press). Discrepancy between definitions of learning disabilities and what schools use: An empirical investigation. Journal of Learning Disabilities.

MacMillan, D. L., Gresham, F. M., Lopez, M. F., \& Bocian, K., (1996). Comparison of students nominated for pre-referral interventions by ethnicity and gender. Journal of Special Education, 30, 133-151.

MacMillan, D. L., Gresham, F. M., Siperstein, G. N., \& Bocian, K. M. (1996). The labyrinth of I.D.E.A.: School decisions on referred students with subaverage general intelligence. American Journal on Mental Retardation, 101, 161-174.

MacMillan, D. L., Siperstein, G. N., \& Gresham, F. M. (1996). Mild mental retardation: A challenge to its viability as a diagnostic category. Exceptional Children, 62, 356-371.

Mercer, C. D., Jordan, L., Allsopp, D. H., \& Mercer, A. R. (1996). Learning disabilities definitions and criteria used by state education departments. Learning Disability Quarterly, 19, 217-232.

Mercer, C. D., Hughes, C., \& Mercer, A. R. (1985). Learning disabilities definitions used by state education departments. Learning Disability Quarterly, 8, 45-55.

Mercer, J. (1973). Labeling the mentally retarded. Berkeley, CA: University of California Press.

Morison, P., White, S. H., \& Feuer, M. J. (Eds.) (1996). The use of $I Q$ tests in special education decision making and planning. Washington, DC: National Academy Press.

National Advisory Committee on Handicapped Children. (1968). Special education for handicapped children: First annual report. Washington, DC: U. S. Department of Health, Education and Welfare.
National Joint Committee on Learning Disabilities. (1981). A new definition of learning disabilities. Learning Disabilities Quarterly, 4, 336-342.

Robinson, H. B., \& Robinson, N. M. (1965). The mentally retarded child. New York: McGraw-Hill

Speece, D. L., \& Harry, B. (in press). Classification for children. In J. W. Lloyd, E. Kameenui, \& D. Chard (Eds.), Issues in educating students with disabilities. Hillsdale, NJ: Lawrence Erlbaum Associates.

Tobias, S., Zibrin, M., \& Menell, C. (1983). Special education referrals: Failure to replicate student-teacher ethnicity interaction. Journal of Educational Psychology, 75, 705-707,

U. S. Department of Education. (1995). Seventeenth annual report to Congress on the implementation of the Individuals with Disabilities Education Act. Washington, DC: Author.

U. S. Office of Education. (1977). Assistance to states for education for handicapped children: Procedures for evaluating specific learning disabilities. Federal Register, 42, 65082-65085.

Walker, H., Block-Pedego, A., Todis, B., \& Severson, H. (1991). School Archival Records Search (SARS): Users guide and technical manual. Longmont, CO: Sopris West.

Walker, H. M. \& Severson, H. (1992). Systematic Screening for Behavior Disorders: Technical Manual. Longmont, CO: Sopris West, Inc.

Zigmond, N. (1993). Learning disabilities from an educational perspective. In G. R. Lyon, D. B. Gray, J. F. Kavanagh, \& N. A. Krasnegor (Eds.), Better understanding of learning disabilities. (pp. 251-272). Baltimore: Paul H. Brookes.

Authors' Note:

The present work was supported, in part, by grants No. H023C20002 and H023C30103 from the U. S. Department of Education. Opinions expressed herein are those of the authors alone and should not be interpreted to have agency endorsement. This article is based, in part, on an earlier paper delivered at the Kennedy Center, Vanderbilt University by the first author.

\section{PERMISSIONS AND COPYRIGHT}

All rights are reserved. No part of this publication may be reproduced, photocopied, faxed, stored in a retrieval system, or transmitted, in any form or by any means, electronic, mechanical, recording or otherwise, without the prior written permission of the publisher.
Back issues are available for sale. Reproduction requires permission and payment of fees. It is illegal and a violation of federal copyright law to reproduce this publication without permission. Direct all inquiries to the permissions editor. 


\title{
NEW 1998 EDITION
}

\section{Free Appropriate Public Education: The Law and Children with Disabilities-Fifth Edition}

\author{
H. Rutherford Turnbull, University of Kansas \\ Ann Turnbull, University of Kansas
}

This definitive resource covers

legislation, case law techniques, due process, parent participation, and much more. The text is completely updated and contains all the substantial amendments made by the 1997 reauthorization of IDEA. The book also reports the pre-1997 provisions of IDEA so that comparisons to the current law can be made. The cases presented in this edition represent those that are widely regarded as "leading" or those that are quite recent and represent an established body of law. By being selective, this text focuses on the most important special education law cases and gives detailed analysis of the court's decisions.

\section{Special Features}

- Completely updated with amendments made by 1997 reauthorization of IDEA

- Detailed analysis of most important cases affecting special education law

- Presents significant pre-1997 provisions of IDEA

- Glossary to explain legal terminology

\section{Contents}

1. Introduction to the American Legal System

2. Federal Policy and Disability

3. Zero Reject

4. Testing, Classification, and Placement

5. Appropriate Education
6. Least Restrictive Appropriate Educational Placement

7. Procedural Due Process

8. Parent Participation and Shared Decision Making

9. Compliance Through the Courts

10. Enforcement of Six Principles and Systems-Change for School Reform

9801/Hardback/448 Pages/ISBN: 0-89108-258-1/\$52.00

Publication Date: December, 1997

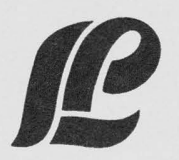

\section{LOVE PUBLISHING COMPANY}

P.O. Box 22353

Denver, CO 80222

303-757-2579 • Fax 303-782-5683 


\section{Professional update}

Teacher Educators for Children with Behavioral Disorders

November 20-22, 1997

Scottsdale Hilton Resort and Villa

Scottsdale, Arizona

Contact: Pat Chipman

TECBD Conference

1131 N. Bronco Court

Gibert, AZ 85223

\section{Learning Disabilities Association of America}

March 11-14, 1998

Hilton Hotel

Washington, DC

Contact: Learning Disabilities Association of America 4156 Library Rd

Pittsburgh, PA 15234

\section{Council for Exceptional Children}

April 15-19, 1998

Annual Conference

Minneapolis, $\mathrm{MN}$

Contact: Council for Exceptional Children

1920 Association Drive

Reston, VA 22091

\section{National Association of School Psychologists}

April 14-18, 1998

Annual Conference

Orlando, FL

Contact: National Association of School Psychologists 4340 East West Highway

Suite 402

Bethesda, MD 20814 